\title{
The Nature of Reducing Compounds Formed from Sucrose by Erwinia carotovora var. atroseptica
}

\author{
By BARBARA M. LUND AND G. M. WYATT \\ Agricultural Research Council Food Research Institute, \\ Colney Lane, Norwich, Norfolk, NOR $70 \mathrm{~F}$
}

(Received I2 April 1973)

\section{SUMMARY}

When grown in a medium containing 2 to $4 \%$ sucrose, Erwinia carotovora var. atroseptica formed two reducing compounds which accumulated in the culture medium. These compounds had the properties of the disaccharides $6-o-\alpha-\mathrm{D}-$ glucopyranosyl-D-fructofuranose (palatinose, isomaltulose) and I- $o-\alpha$-D-glucosylfructose.

\section{INTRODUCTION}

When strains of Erwinia carotovora var. atroseptica were grown in a medium containing $2 \%(\mathrm{w} / \mathrm{v})$ sucrose, a compound accumulated which reduced 2,3,5-triphenyltetrazolium chloride (Moustafa \& Whittenbury, 1970). The ability to produce this reducing material when grown in a sucrose medium has subsequently been used to differentiate $E$. carotovora var. atroseptica from $E$. carotovora var. carotovora (Graham, 1971). The reducing substance was not glucose, fructose or 2-keto-gluconate (Moustafa \& Whittenbury, I970), and D. C. Graham (personal communication) demonstrated by thin-layer chromatography that two reducing compounds were formed. Neither compound was 3-ketosucrose, which is produced by Agrobacterium tumefaciens (Bernaerts \& De Ley, I963). Graham suggested that they were tri- or tetra-saccharides. This paper concerns the nature of these reducing compounds.

\section{METHODS}

Sugars. The following sugars were used, or are referred to, as reference compounds: glucose, fructose, $\beta$-D-fructofuranosyl- $\alpha$-D-glucopyranose (sucrose), 3-o- $\alpha$-D-glucopyranosyl-D-fructose (turanose), 4- $o$ - $\alpha$-D-glucopyranosyl-D-fructose (maltulose), 5-o- $\alpha$-D-glucopyranosyl-D-fructopyranose (leucrose), 6- $o-\alpha$-D-glucopyranosyl-D-fructofuranose (palatinose, isomaltulose), 4- $o$ - $\alpha$-D-glucopyranosyl-D-glucopyranose (maltose), 4-o- $\beta$-D-glucopyranosyl-D-glucopyranose (cellobiose). Glucose, fructose, sucrose, turanose, palatinose, maltose and cellobiose were obtained from the Sigma Chemical Co., London. A sample of leucrose, used for mass spectrometry, was obtained from Professor E. J. Bourne.

Enzymes. Yeast $\alpha$-glucosidase and almond $\beta$-glucosidase were obtained from the Sigma Chemical Co.

Bacteria. Erwinia carotovora var. atroseptica strain GI 20 (Lund \& Nicholls, 1970) was originally obtained from Dr D. C. Graham. Other strains were laboratory isolates from potatoes. E. carotovora var. carotovora was a laboratory isolate from cauliflower.

Production of culture liquid containing reducing compounds. The bacteria were grown in shaken flasks for 3 days at $25{ }^{\circ} \mathrm{C}$ in a medium containing: peptone (Difco), I \% (w/v); beef 
extract powder (Lab. Lemco), $0.4 \%(\mathrm{w} / \mathrm{v})$; sucrose, $4 \%(\mathrm{w} / \mathrm{v})$; (Graham, 197I). The bacteria were removed by centrifugation and the culture liquid was stored at $-25^{\circ} \mathrm{C}$.

Paper chromatography. Descending chromatography on Whatman $3 \mathrm{MM}$ paper was used with the following solvent systems: (i) isopropanol-water $(4: \mathrm{I}, \mathrm{v} / \mathrm{v})$; (ii) $n$-butanol-pyridinewater $(5: 3: 2$, by vol.); (iii) $n$-butanol-acetic acid-water (1 $2: 3: 5$, by vol.). The developing times were 48 to $54 \mathrm{~h}$ for solvents (i) and (ii) and $\mathrm{I} 7 \mathrm{~h}$ for solvent (iii). Disaccharides from the crude culture liquid were purified by band chromatography on Whatman $3 \mathrm{MM}$ paper using solvent system (ii); two successive separations were made, washed paper being used for the second to minimize impurities from the paper. Results were expressed as $R_{g}$ values, where $R_{g}$ is the distance travelled by the compound/distance travelled by glucose.

Paper electrophoresis. The apparatus used was supplied by Locarte Co., 24 Emperor's Gate, London, SW 7. Electrophoresis was on a strip of Whatman 3MM paper Io $\mathrm{cm}$ wide, with 0.1 M-sodium borate buffer, $\mathrm{pH}$ I0, as electrolyte (Avigad, I959; Foster, I953). One thousand volts were applied $(20 \mathrm{~V} / \mathrm{cm})$ for $5 \mathrm{~h}$, giving a starting current of 50 to $60 \mathrm{~mA}$. Sugars were detected by spray reagent $D$ (see below). The apparent distances of migration were corrected for movement due to electroendosmosis by reference to movement of 2,3,4,6-tetramethylglucose; under the conditions employed the true distance of migration of glucose was about $20 \mathrm{~cm}$. Results were expressed as $M_{g}$ values, where $M_{g}$ is the distance travelled by the compound/distance travelled by glucose.

Selective spray reagents. The spray reagents used were: A, silver nitrate-ammonia reagent (Partridge, 1948) for detection of reducing sugars; B, urea-phosphoric acid (Wise, Dimler, Davis \& Rist, I955) for detection of ketoses; C, aniline-diphenylamine-phosphoric acid for distinguishing between I,4-linked and I,6-linked glucosaccharides (Schwimmer \& Bevenue, 1956); D, aniline phosphate (Frahn \& Mills, I959; Hough, Jones \& Wadman, 1950) for reducing sugars and sucrose; E, glucose oxidase reagent for blood sugar determination (Boehringer Co. Ltd) to confirm the identity of glucose on chromatograms.

Acid hydrolysis of sugars. Hydrolysis was effected by heating in a boiling water bath in $0.5 \mathrm{~N}$-sulphuric acid for $2 \mathrm{~h}$. After neutralizing, the hydrolysate was evaporated to dryness under reduced pressure and the sugars extracted with hot ethanol.

Enzymic hydrolysis of sugars. Susceptibility to $\alpha$ - and $\beta$-glucosidase was tested by superimposing enzyme solution on the sugar spot on Whatman $3 \mathrm{MM}$ paper and subsequently separating the hydrolysis products by chromatography (Williams \& Bevenue, 195I).

Reduction of sugars. A $10 \mathrm{ml}$ sample of crude culture liquid was adjusted to $\mathrm{pH} 8$, mixed with $2 \mathrm{ml}$ of $5 \%(\mathrm{w} / \mathrm{v})$ sodium borohydride solution and placed overnight at $\mathrm{I}{ }^{\circ} \mathrm{C}$ (Bragg \& Hough, 1957). Completion of reduction was checked by acidifying a sample to $\mathrm{pH} 5$, to decompose residual borohydride, and testing the ability of the residual sample to give a precipitate when heated with an equal volume of Benedict's reagent. When reduction was complete, the solution was adjusted to $\mathrm{pH} 5$ to decompose the borohydride. Sodium ions were removed by treatment with Dowex $50 \mathrm{~W}-\mathrm{X} 8\left(\mathrm{H}^{+}\right)$, the liquid was evaporated to dryness under reduced pressure and borate removed by repeated evaporation of methanol from the residue which was finally redissolved in distilled water.

Mass spectra. Compound II (see Results and Discussion) was purified by elution from paper chromatograms. Reference compounds were used as supplied, without further purification. Per(trimethylsilyl)ethers of sugars were prepared as follows: to $0 . \mathrm{I}$ to $\mathrm{I} \cdot 0 \mathrm{mg}$ of sugar was added 50 to $100 \mu \mathrm{l}$ of Tri-Sil ' $\mathrm{Z}$ ' reagent, containing I $5 \mathrm{~m}$-equiv. $\mathrm{N}$-trimethylsilylimidazole/ml in silylation-grade pyridine (Phase Separations Ltd, Deeside Industrial Estate, Queensferry, Flintshire); the reaction was allowed to proceed for $\mathrm{I} h$ at room temperature in a sealed ampoule. Mass spectra were recorded on an AEI MS 902 double-focusing mass spectrometer 
at an ionizing potential of $70 \mathrm{eV}$ and an ion chamber temperature of $220^{\circ} \mathrm{C}$. Intensities, expressed relative to the peak at $m / e$ 36I (Kamerling, Vliegenthart, Vink \& de Ridder, I97I ; I972) are given in parenthesis for the molecular ion $\left(\mathrm{M}^{+}\right)$, for peaks above $m / e 360$ with relative intensities greater than I \%, and for peaks between $m / e 200$ and $m / e 360$ with relative intensities greater than $10 \%$.

\section{RESULTS AND DISCUSSION}

In preliminary work, when samples of the culture liquid from Erwinia carotovora var. atroseptica strain GI 20 were analysed by paper chromatography in solvent (i) for $\mathrm{I} 8 \mathrm{~h}$ and spraying with reagent $\mathrm{A}$, only one reducing compound was detected. In subsequent work longer developing times were used (see Methods) resulting in resolution of two reducing compounds, I and II. After chromatography for I $8 \mathrm{~h}$ in solvent (i), $R_{g}$ values were as follows: fructose, I.I I I II (not resolved), 0.68 ; lactose, $0.4 \mathrm{I} ; \alpha$-oxoglutarate, 0.29 . Chromatography for $17 \mathrm{~h}$ in solvent (iii) gave $R_{g}$ values: fructose, I $\cdot \mathrm{I}$; I+II (not resolved), 0.56 ; lactose, $0.45 ; \alpha$-oxoglutarate, $2 \cdot 0$. Since the $R_{g}$ values of I+II in contrast to $\alpha$-oxoglutarate were similar in the neutral and the acidic solvents, it was concluded that compounds I and II were not acidic. Chromatography for $54 \mathrm{~h}$ in solvent (i) resolved compounds I and II and showed that they differed in mobility from the reducing compound, 3-ketosucrose, present in the culture liquid of sucrose-grown Agrobacterium tumefaciens, confirming D. C. Graham's unpublished report.

Further studies of the properties of these compounds (Table $I$ ) were made after purification by chromatography. The $R_{g}$ values indicated that I and II were probably disaccharides. Both were ketose-containing compounds which gave a blue colour with spray reagent $\mathrm{B}$ and, after acid hydrolysis, released glucose and fructose in approximately equal amounts as judged by intensity of spots on chromatograms and comparison with standards. That glucose was released on hydrolysis was confirmed by spraying the chromatogram with glucose oxidase reagent, spray D. After reduction of the crude culture liquid containing I and II, followed by acid hydrolysis, glucose was the only reducing hexose detectable on paper chromatograms; thus fructose probably provided the terminal reducing group of these compounds. Both I and II were hydrolysed by $\alpha$-glucosidase to give glucose and fructose. They were not attacked by $\beta$-glucosidase under conditions which hydrolysed cellobiose, indicating that I and II were $\alpha$-glucosyl-fructoses.

Paper chromatography and reactions with spray reagents distinguished I from $\mathbf{I}-o-\alpha-$ glucosylfructose (Avigad, I959), sucrose, turanose, maltulose (Avigad, I959; Täufel, Ruttloff \& Täufel, 1967), and leucrose (Wise et al. 1955; Stodola, Sharpe \& Koepsell, 1956) (Table I). Compound I showed the same $R_{g}$ value as palatinose by paper chromatography in solvent systems (i) and (ii) and the same $M_{g}$ value as palatinose by paper electrophoresis. With the aniline-diphenylamine-phosphoric acid reagent, spray $\mathrm{C}$, both I and palatinose gave a yellow-green colour similar to that reported for I,6-linked glucosaccharides. These properties indicate that I was palatinose, this conclusion being supported by the value of its optical rotation. The measured optical rotation of I was slightly lower than that of the crystalline reference compound, probably because the sample of I retained a slight impurity and was not crystallized.

By chromatography and its reactions with spray reagents, II could be distinguished from sucrose, turanose, maltulose, leucrose, and palatinose (Table I). With the anilinediphenylamine-phosphoric acid reagent, spray C, II gave a red colour, which has previously been reported as being characteristic of $\mathrm{I}-o-\alpha$ - and $\mathrm{I}-o-\beta$-glucosylfructose, but not of other $\alpha$-glucosylfructoses (Avigad, I959). The chromatographic mobility of II was less than 


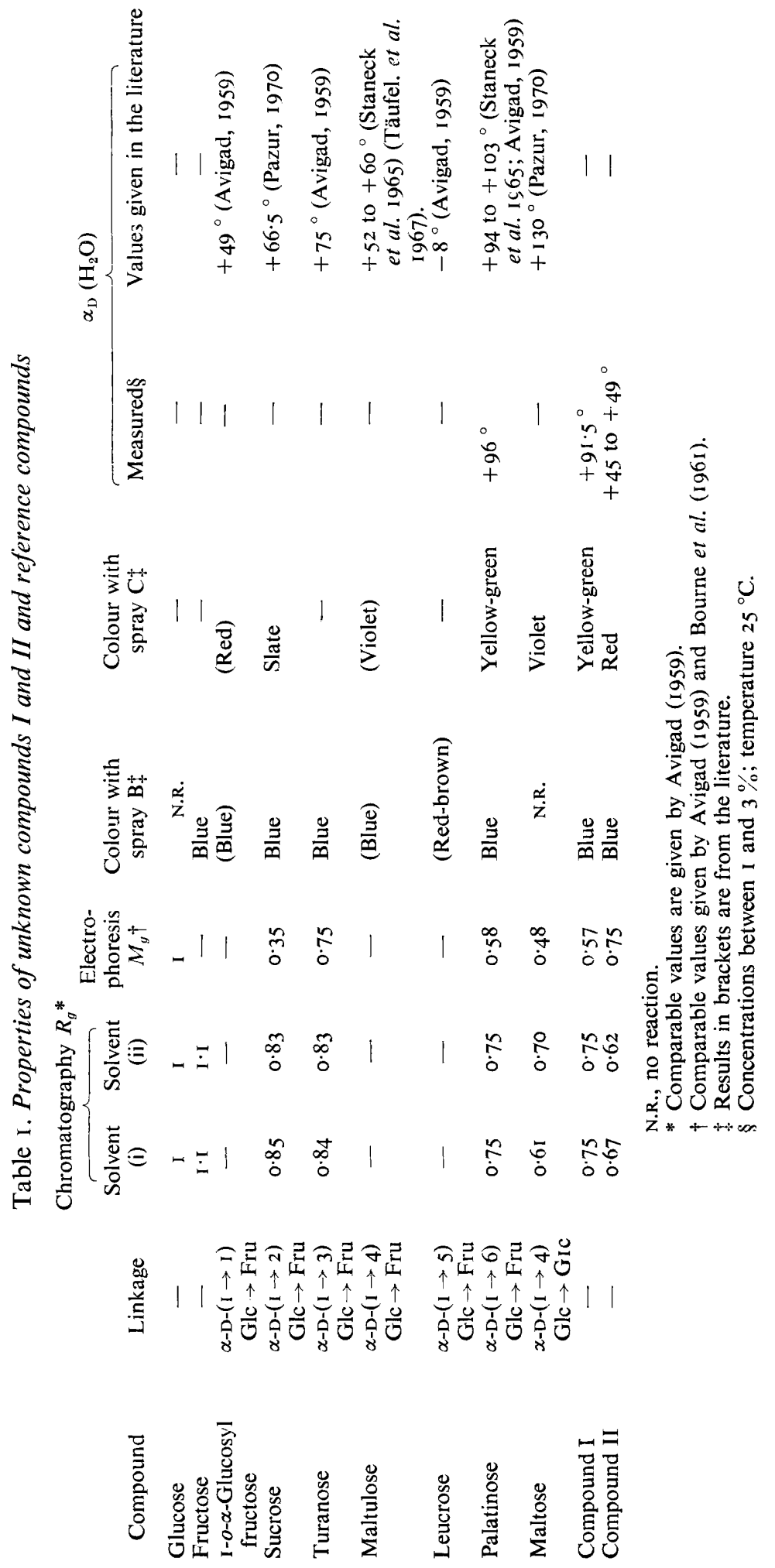


that of the other $\alpha$-glucosylfructoses tested and was close to that of maltose; similar results were reported for I-o- $\alpha$-glucosylfructose by Avigad (I959) and by Chiba \& Shimomura (197I). The electrophoretic mobility of II $\left(M_{g} 0 \cdot 75\right)$ was comparable to those reported in the same buffer for I- $o-\alpha$-glucosylfructose $\left(M_{g} 0 \cdot 70\right)$ and I- $o$ - $\beta$-glucosylfructose $\left(M_{g} 0 \cdot 68\right)$ by Avigad (I959) and for I-o- $\beta$-glucosylfructose $\left(M_{g} 0 \cdot 74\right)$ by Bourne, Hutson \& Weigel (I96I). The optical rotation of purified II confirmed its probable identity as I- $o$ - $\alpha$-glucosylfructose. An authentic sample of $\mathrm{I}-0$ - $\alpha$-glucosylfructose was not available. Further evidence for the identity of II was obtained from mass spectrometry of the per(trimethylsilyl) (TMS) derivative of this compound and of other $\alpha$-glucosylfructoses. For II the most significant peaks were: $m / e$ 9I $8\left(\mathrm{M}^{+}, 0 \cdot \mathrm{I} 5\right), 8 \mathrm{I} 3(\mathrm{I} \cdot 0), 723(\mathrm{I} \cdot 0), 684(\mathrm{I} 4 \cdot \mathrm{I}), 569(4 \cdot 5), 539(5 \cdot \mathrm{I}), 525(\mathrm{I} \cdot 0)$, $45 \mathrm{I}(4 \cdot 5), 437(505 \cdot 0), 435(8 \cdot \mathrm{I}), 407(\mathrm{I} \cdot 5), 393(\mathrm{I} \cdot 0), 36 \mathrm{I}$ (I00), $319(43 \cdot 4), 307$ (I $5 \cdot 2), 305$ (I3.6), 23 I (I2.6), 230 (I3.I), 217 (437), 204 (276). Most of these peaks correspond to fragment ions previously reported as characteristic of TMS-glucosyl-aldohexoses and TMSglucosylfructoses (Kamerling et al. 197I; 1972). The spectrum agreed closely with that previously reported for I-o- $\beta$-glucosylfructose (Kamerling et al. 1972), and spectra for sucrose, turanose, leucrose and palatinose were also similar to the spectra reported by these authors. A distinctive feature of the mass spectrum of II was the intense ion at $m / e$ 437, shown by these authors to differentiate the $\mathrm{I} \rightarrow \mathrm{I}$ and $\mathrm{I} \rightarrow 2$ glucosylfructoses from the $\mathrm{I} \rightarrow 3, \mathrm{I} \rightarrow 4, \mathrm{I} \rightarrow 5$ and $\mathrm{I} \rightarrow 6$ hexosylfructoses. Previous tests having shown that II was not $\mathrm{I} \rightarrow 2$ glucosylfructose, the mass spectral data confirmed its identity as a I- $o$-glucosylfructose.

No quantitative estimations were made of compounds I and II, but they were apparently formed in about equal amounts. Examination by paper chromatography in solvent (ii) of culture filtrates of ten further isolates of Erwinia carotovora var. atroseptica also showed reducing compounds corresponding in position to the same pair of disaccharides; these compounds were not detected in cultures of a strain of E. carotovora var. carotovora.

Production of reducing disaccharides containing glucose and fructose by $\alpha$-D-glucosyl transfer from sucrose has previously been reported for several bacteria. Weidenhagen \& Lorenz (1957) obtained nearly $90 \%$ conversion of sucrose into palatinose by a red-pigmented bacterium, named Protaminobacter rubrum, isolated from a sugar-beet processing factory (Weidenhagen, 196I). Leucrose and palatinose have been isolated as by-products during dextran production from sucrose by Leuconostoc mesenteroides (Stodola et al. 1956; Sharpe, Stodola \& Koepsell, 1960) and by Streptococcus bovis (Bailey \& Bourne, I959; Bourne et al. I96I). There are few reports of microbial production of I-o- $\alpha$-glucosylfructose. A mixture of palatinose and $\mathrm{I}-\mathrm{o}-\alpha$-glucosylfructose in the ratio of about Io to I, together with traces of other di- and tri-saccharides, was produced by the action of a haploid-yeast $\alpha$-glucosidase on sucrose (Avigad, I959). More recently, formation of a mixture of I-o- $\alpha$-glycosylfructose, turanose, maltulose, isomaltose and nigerose was reported when phenyl- $\alpha$-glucoside and D-fructose were incubated with brewer's yeast $\alpha$-glucosidase (Chiba \& Shimomura, 1971).

We are grateful to Dr F. A. Isherwood for his interest and advice, to Professor E. J. Bourne for the gift of a sample of leucrose, to Dr D. S. Robinson for advice on preparation of trimethylsilyl derivatives, to $\mathrm{Mr} \mathrm{R}$. Self for mass spectral measurements and to $\mathrm{Mrs}$ P. M. Yeates for technical assistance. 


\section{REFERENCES}

AvigAD, G. (I959). Synthesis of glucosylfructoses by the action of a yeast $\alpha$-glucosidase. Biochemical Journal 73, $587-593$.

Bailey, R. W. \& Bourne, E. J. (1959). Formation of leucrose in dextran-producing cultures of Streptococcus bovis. Nature, London 184, 904-905.

Bernaerts, M. J. \& De LeY, J. (1958). 3-Ketoglycosides, new intermediates in the bacterial catabolism of disaccharides. Biochemica et biophysica acta $3^{0}, 66 \mathrm{I}-662$.

Bourne, E. J., Hutson, D. H. \& Weigel, H. (1960). Paper ionophoresis of glucopyranosyl-fructoses and other substituted fructoses. Chemistry and Industry, pp. I I I I-I I I 2.

Bourne, E. J., Hutson, D. H. \& WEIGEL, H. (I96I). Oligosaccharides in dextran-producing cultures of Streptococcus bovis. Biochemical Journal 79, 549-553.

BragG, P. D. \& Hough, L. (1957). Quantitative aspects of reductions of carbohydrates by potassium borohydride. Journal of the Chemical Society pp. 4347-4352.

Chiba, S. \& Shimomura, T. (I97I). Studies on enzymatic synthesis of oligosaccharides. I. $\alpha$-D-glucopyranosyl-D-fructoses synthesized by the transglucosidation reaction of Brewer's yeast $\alpha$-glucosidase. Agricultural and Biological Chemistry 35 (8), I292-1 297.

Foster, A. B. (1953). Ionophoresis of some disaccharides. Journal of the Chemical Society 982-986.

Frahn, J. L. \& Mills, J. A. (1959). Paper ionophoresis of carbohydrates. I. Procedures and results for four electrolytes. Australian Journal of Chemistry r2, 65-89.

GrahaM, D. C. (197I). Identification of soft rot coliform bacteria. In Proceedings of the Third International Conference on Plant Pathogenic Bacteria, Wageningen, pp. 273-279. Edited by H. P. Mass Geesteranus. Wageningen: Centre for Agricultural Publishing and Documentation.

Hough, L., Jones, J. K. N. \& Wadman, W. H. (1950). Quantitative analysis of mixtures of sugars by the method of partition chromatography. V. Improved methods for the separation and detection of the sugars and their methylated derivatives on the paper chromatogram. Journal of the Chemical Society, pp. I 702-1 706 .

Kamerling, J. P., Vliegenthart, J. F. G., VinK, J. \& de Ridder, J. J. (I971). Mass spectrometry of pertrimethylsilylaldosyl oligosaccharides. Tetrahedron $27,4275-4288$.

Kamerling, J. P., Vliegenthart, J. F. G., VINK, J. \& DE RidDER, J. J. (I972). Mass spectrometry of pertrimethylsilyl-oligosaccharides containing fructose units. Tetrahedron $28,4375-4387$.

Lund, B. M. \& Nicholls, J. C. (I970). Factors influencing the soft-rotting of potato tubers by bacteria. Potato Research 13, 2 I0-2I4.

Moustafa, F. A. \& Whittenbury, R. (1970). A comparison of some phytopathogenic and non-pathogenic pseudomonads. Phytopathologische Zeitshrift 67 (1), 63-72.

Partridge, S. M. (I948). Filter paper partition chromatography of sugars. Biochemical Journal 42, 238-250.

Pazur, J. H. (1970). Oligosaccharides. In The Carbohydrates, 2nd edn, vol. IIA, pp. 69-137. Edited by W. Pigman and D. Horton. New York, London: Academic Press.

Sharpe, E. S., Stodola, F. H. \& Koepsell, H. J. (I960). Formation of isomaltulose in enzymatic dextran synthesis. Journal of Organic Chemistry 25, 1062-1063.

Schwimmer, S. \& Bevenue, A. (1956). Reagent for differentiation of I,4- and I,6-linked glucosaccharides. Science, New York 123, 543-544.

StAnĚK, J., ČRnÝ, M. \& PACÁK, J. (1965). The Oligosaccharides. Translated by K. Meyer. New York: Academic Press.

Stodola, F. H., Sharpe, E. S. \& Koepsell, H. J. (1956). The preparation, properties and structure of the disaccharide leucrose. Journal of the American Chemical Society 78, 25 I4.

TÄUfel, A., Ruttloff, H. \& TÄUfeL, K. (1967). Synthesis of maltulose by intestinal $\alpha$-D-glucosidases. Carbohydrate Research 5, 223-225.

WeIDENHAGEN, R. (I96I). Biochemical reactions of sucrose. Zucker, 456-462.

Weidenhagen, R. \& LoRenZ, S. (I957). Palatinose (6-( $\alpha$-glucopyranosido)-fructofuranose), ein neues bakterielles Umwandlungsprodukt der Saccharose. Zeitschrift für die Zuckerindustrie 82, 533-534.

Williams, K. T. \& Bevenue, A. (I95I). A simple technique for the identification of raffinose and sucrose by enzymic hydrolysis on paper chromatograms and the subsequent separation of the hydrolyzed products by paper chromatography. Science, New York $1 \mathbf{1 3}_{3}, 582$.

Wise, C. S., Dimler, R. J., Davis, H. A. \& Rist, C. E. (I955). Determination of easily hydrolysable fructose units in dextran preparations. Analytical Chemistry 27, 33-36. 